
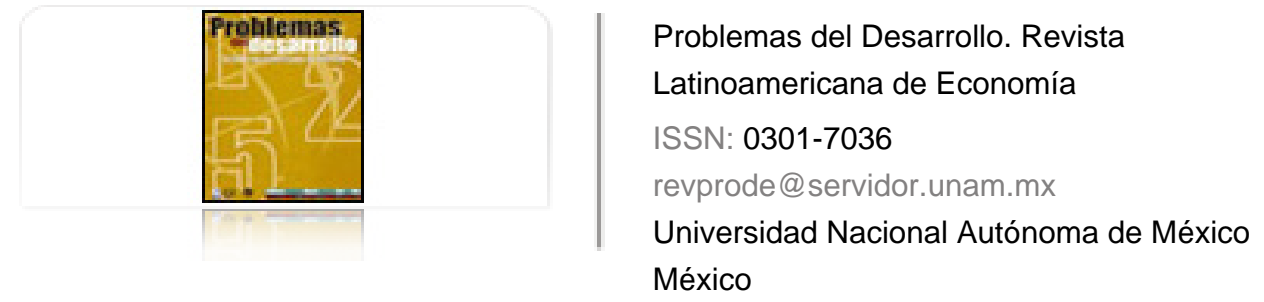

Calderón, Cuauhtémoc; Sánchez, Isaac

Crecimiento económico y política industrial en México

Problemas del Desarrollo. Revista Latinoamericana de Economía, vol. 43, núm. 170, julio-septiembre, 2012, pp. $125-154$

Universidad Nacional Autónoma de México

Distrito Federal, México

Disponible en: http://www.redalyc.org/articulo.oa?id=11823063006

- Cómo citar el artículo

- Número completo

- Más información del artículo

Página de la revista en redalyc.org

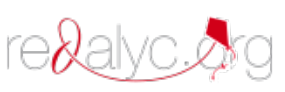

Sistema de Información Científica

Red de Revistas Científicas de América Latina, el Caribe, España y Portugal Proyecto académico sin fines de lucro, desarrollado bajo la iniciativa de acceso abierto 
Revista Problemas del Desarrollo, 170 (43), julio-septiembre 2012

\title{
Crecimiento económico Y POLÍTICA INDUSTRIAL EN MÉXICO ${ }^{1}$
}

\author{
Cuauhtémoc Calderón** e Isaac Sánchez***
}

Fecha de recepción: 4 de septiembre de 2011. Fecha de aceptación: 28 de febrero de 2012.

\begin{abstract}
RESUMEN
En este artículo se analiza un problema que resulta crucial para el desarrollo económico de México: el bajo crecimiento económico y la consecuente imposibilidad para generar los empleos necesarios. Se supone, en base a la teoría del crecimiento kaldoriana, que dicha problemática es resultado de errores de política económica, básicamente el abandono de la política industrial activa orientada al cambio estructural y desarrollo económico. Se proporciona evidencia que da cuenta de la alta correlación entre el bajo crecimiento económico y el bajo crecimiento del producto manufacturero, resultado que es compatible con los hallazgos de otros investigadores. De haberse implementado una política industrial activa, la tasa de crecimiento del sector manufacturero sería mayor a la observada y ello contribuiría a un mejor desempeño económico global. Por su importancia, el artículo expone las razones por las cuales se abandonó esta clase de política industrial y sugiere retomarla.
\end{abstract}

Palabras clave: bajo crecimiento, empleo, política industrial, México.

\section{Economic Growth and Industrial Policy in Mexico}

\begin{abstract}
This paper analyzes a problem that proves crucial for the economic development of Mexico: slow economic growth and the subsequent inability to generate necessary employment. On the basis on Kaldorian growth theory, it is supposed that this problem is the result of economic policy errors, in essence the abandonment of active industrial policy in favor of structural change and economic development. Evidence is provided which highlights the high correlation between slow economic growth and slow growth in manufacturing output, a result consistent with the findings of other researchers. Having implemented an active industrial policy, the growth rate in the manufacturing sector would prove greater than that observed and would improve global economic development. Given the importance of this type of industrial policy, this paper outlines the reasons why the policy was abandoned and suggests that it be reinstated.

Key Words: slow growth, employment, industrial policy, Mexico

1 Los autores agradecen la evaluación y comentarios realizados por tres dictaminadores anónimos.

** Profesor-investigador de El Colegio de la Frontera Norte, Miembro del sNI nivel II. Correo electrónico: calderon@colef.mx

*** Profesor-investigador de la Universidad Autónoma de Ciudad Juárez, México, Correo electrónico isaac. sanchezuacj.mx. Candidato a Investigador Nacional del Sistema Nacional de Ivestigadores (SNI).
\end{abstract}




\section{CROISSANCE ÉCONOMIQUE ET POLITIQUE INDUSTRIELLE AU MEXIQUE Résumé}

Dans cet article, il est procédé à l'analyse d'un problème qui s'avère crucial pour le développement économique du Mexique : la faible croissance économique et l'impossibilité de générer les emplois nécessaires qui en découle. Il est supposé, en se basant sur la théorie kaldorienne de la croissance, que cette problématique résulte d'erreurs de politique économique, fondamentalement de l'abandon de la politique industrielle active orientée vers le changement structurel et le développement économique. Il est fourni une preuve de la forte corrélation entre la faible croissance économique et la faible croissance de la production manufacturière, ce qui est conciliable avec ce qu'ont mis à jour d'autres chercheurs. Si une politique industrielle active avait été menée, le taux de croissance du secteur manufacturier serait plus élevé que celui observé et cela contribuerait à de meilleures performances économiques globales. Compte tenu de leur importance, l'article expose les raisons pour lesquelles ce type de politique industrielle a été abandonnée, et il suggère d'y revenir.

Mots clés : faible croissance, emploi, politique industrielle, Mexique.

\section{CRESCIMENTO ECONÓMICO E POLÍTICA INDUSTRIAL NO MÉXICO \\ Resumo}

Nste artigo se discute uma questão que é crucial para o desenvolvimento económico do México: o baixo nível de crescimento económico e a consequente incapacidade de gerar os empregos necessários. Presume-se, com base numa teoria kaldoriana do crescimento, que este problema é resultado de erros da política económica, basicamente o abandono da política industrial ativa, orientada para promover a transformação estrutural e o desenvolvimento económico. No artigo se fornece provas de que dão conta da alta correlaçáo existente entre o baixo crescimento econômico e o baixo crescimento da produçáo manufatureira, resultado que é coerente com os resultados de outros pesquisadores. Caso fosse implementada uma política industrial ativa, a taxa de crescimento do setor manufatureiro seria maior do que aquela observada e isto contribuiria para um melhor desempenho económico global.

Devido à sua importância, o artigo discute as razóes pelas quais se abandonou este tipo de política industrial e sugere que estas sejam retomadas.

Palavras-chave: baixo crescimento, emprego, política industrial, México.

墨西哥的经济低增长、就业或失业与产业政策

摘要

本文讨论了对, 墨西哥经济发展至关重要的一个问题：经济低增长导致的后 果是无法提供所需要的就业机会。根据卡尔多的增长理论, 可以假定这个 问题的产生是经济政策失误的结果, 即基本上是放弃了实现结构变化和经 济发展的积极的工业政策。证据表明，考虑到经济低增长和制造业低增 长之间的相关关系, 与他人的研究发现也是高度一致的。若要实施积极的 工业政策, 制造业的增长率将大于观测值, 这将有助于全球经济更好的改 善。考虑到它的重要性, 本文解释了放弃这种产业政策的理由, 并建议重 新启用这项政策。

关键词：低增长, 就业, 工业政策, 墨西哥 


\section{INTRODUCCIÓN}

México en su historia económica moderna ha atravesado por diferentes fases de alto y bajo crecimiento. ${ }^{2}$ Particularmente de 1982 a la fecha, la economía mexicana ha presentado un muy bajo crecimiento. El crecimiento ha sido insuficiente como para generar el número de empleos que requiere una población que cada ańo va en aumento. Sin crecimiento económico y empleo no se generan las condiciones necesarias para superar los obstáculos que impiden alcanzar el desarrollo económico del país.

La constante del periodo 1982-2010 es una tasa de crecimiento económico promedio del PIB per cápita por debajo de $1.0 \%$ y más recientemente (1993 a 2011) una estabilidad macroeconómica decepcionante, ya que aunque se ha reducido la tasa de inflación, se ha mantenido un déficit moderado en las finanzas públicas y controlado el déficit externo, existe un agudo problema de desempleo y crisis macroeconómicas recurrentes (en 1982, 1986, 1995, 2001 y 2009).

En vista de lo anterior, el objetivo general de este artículo consiste en poner en evidencia que el crecimiento económico en México ha sido sumamente bajo desde la década de los ochenta a la fecha. Lo que obedece, principalmente, a las políticas neoliberales impuestas por el actual modelo económico, derivado de las reformas del consenso de Washington, que trajeron consigo un crecimiento insuficiente del sector industrial manufacturero. Con el artículo se pretende contribuir a la literatura y debate sobre el bajo crecimiento económico en México.

Se estructuró en cuatro partes; en la primera se presenta el marco teórico que sirve como referencia en la explicación de la etapa actual de bajo crecimiento y se dan sumariamente las explicaciones que ofrece la teoría kaldoriana. En la segunda parte se hace una revisión de la literatura que permite contrastar la hipótesis sostenida en este trabajo de investigación respecto a otros trabajos, lo que permite realizar un diagnóstico más amplio del problema. En la tercera parte se demuestra la

2 De acuerdo con Esquivel (2010), la economía mexicana ha transitado por cuatro etapas al menos; la primera comienza con la recuperación de los estragos causados por la Gran Depresión y culmina alrededor de 1970; durante este periodo la economía se caracterizó por un rápido crecimiento acompańado de una relativa estabilidad de precios. La segunda etapa transcurrió entre 1970 y 1982, época en la que se continuó creciendo pero a costa de una mayor inestabilidad macroeconómica. Durante la tercera etapa, de 1982 a 1994, el país cursó un importante periodo de ajuste económico, choques externos negativos y varias reformas económicas. Por último de 1995 a la fecha, la economía ha regresado lentamente a la estabilidad macroeconómica, aunque con un crecimiento económico relativamente bajo. También revisó a Moreno-Brid y Ros (2009), para una caracterización y explicación alternativa de las etapas de la economía mexicana. 
existencia del bajo crecimiento económico, tanto en términos de producto per cápita y de empleo; además de exponerse la fuerte correlación que exhibe con la insuficiencia dinámica manufacturera. ${ }^{3}$ En la cuarta parte se analiza la inexistencia actual de una política industrial activa implementada por el Estado, tema preocupante a la luz de la información mostrada en las secciones anteriores.

\section{BAJO CRECIMIENTO E INDUSTRIAS MANUFACTURERAS}

La búsqueda del progreso económico ha sido una preocupación constante de los economistas, y fue Smith (2004) quien sentó las bases para las modernas aportaciones en la materia. Para este autor, la principal fuente de la riqueza de las naciones y regiones se encuentra en la división del trabajo, especialmente en las actividades manufactureras, dado que genera una mayor especialización en los trabajadores y fomenta la inventiva e imaginación, lo que produce un mayor rendimiento por unidad de trabajo (productividad).

La división del trabajo es la causa de los aumentos en la productividad y por tanto es un factor crucial del mayor o menor crecimiento económico. Dado que Smith entendía que las relaciones de causalidad son bastante complejas, suponía que a su vez la división del trabajo tenía su origen en la extensión del mercado, ya que entre más grande sea el mercado (demanda) mayor será la extensión en la cual la diferenciación y especialización son llevadas a cabo y con ello se da una mayor productividad. De esta forma, la división del trabajo en las manufacturas es una consecuencia de la extensión del mercado, pero la extensión del mercado resulta de una mayor división del trabajo.

Es en las manufacturas donde se genera tal clase de círculos virtuosos para la economía; para Smith sólo en ellas se presentan rendimientos crecientes a escala, es decir, cada que se aumentan los insumos productivos, la producción se incrementa en una proporción mayor. Los casos de China y la mayoría de países asiáticos (Taiwán, Singapur, Malasia, Japón, Hong Kong) ofrecen evidencia aplastante en torno a la importancia que tienen los procesos industrial-manufactureros para una economía emergente. A pesar de que ciertos trabajos de corte sociológico han puesto en duda las ideas de Smith con base en la aparición de las modernas actividades de servicios. ${ }^{4}$

3 El término hace referencia al bajo crecimiento observado de la industria manufacturera.

4 Los servicios modernos en las ramas de transportes y telecomunicaciones casi siempre están asociados a un proceso manufacturero; aun en la era de la información siguen siendo las actividades manufactureras el motor del crecimiento económico, aunque debe reconocerse la importancia creciente de algunos servicios - principalmente los vinculados a la informática. 
Las ideas de Smith serían ampliadas y mejoradas muchos años más tarde por Young (1928) y otros economistas del desarrollo, ${ }^{5}$ para quienes la industria se constituía en el motor del crecimiento económico, ya sea por la existencia de rendimientos crecientes a escala o bien por sus encadenamientos productivos con el resto de sectores de actividad económica. En especial, Prebisch (1957) suponía que la industrialización era clave para superar las relaciones de dependencia existentes entre el centro y la periferia, ya que la elaboración de productos manufacturados por parte de los países periféricos-América Latina-, ayudaría a mejorar la relación de términos de intercambio y con ello a superar la restricción al crecimiento como consecuencia de la balanza de pagos casi siempre deficitaria. Para dicho autor, era necesario incorporar el progreso técnico en la industria y aprovechar sus frutos para nuevos procesos de ese tipo, lo que provoca un proceso acumulativo, dinámico y expansivo.

Para mediados de los sesenta, Kaldor (1966) estableció con claridad a través de tres leyes la importancia que tiene la industria manufacturera para el progreso económico. La primera de estas leyes indica que el crecimiento del producto total se encuentra determinado por el crecimiento de las manufacturas; de forma explícita Kaldor consideraba que las manufacturas representan el motor del crecimiento económico y con ello estableció, al igual que los economistas del desarrollo, que las actividades en las cuales se especializa un país o región son determinantes del éxito o fracaso económico.

Bajo el enfoque kaldoriano, las manufacturas, por sus fuertes efectos de encadenamiento hacia adelante y hacia atrás, se constituyen en el núcleo o procesador central de una economía, no así en el único sector de interés. Las manufacturas y su crecimiento son responsables del crecimiento de la producción global.

La industrialización está íntimamente ligada al cambio estructural y desarrollo económico de los países; ella es portadora del progreso social en todos los órdenes (Martínez del Campo, 1985:15). ${ }^{6}$

5 Véase Toner (1999) y Ros (2004) para una presentación amplia de las ideas de los economistas del desarrollo.

6 Esta ley ha sido verificada en innumerables investigaciones. En el plano internacional destaca el trabajo de Wells y Thirlwall (2003); ellos demuestran la importancia del sector manufacturero en una muestra de países africanos. La relevancia de las manufacturas para el crecimiento económico en México se demuestra en los trabajos de Ocegueda (2003); Díaz-Bautista (2003); Loría (2009) y Sánchez (2010); este último utiliza tanto series de tiempo, como panel de datos para demostrar que en México las manufacturas son el motor del crecimiento económico. 
La segunda ley o ley Verdoorn-Kaldor señala que un rápido crecimiento del producto industrial manufacturero, a través de los rendimientos crecientes a escala, conducirá a un rápido crecimiento de la productividad laboral industrial; así la productividad y el progreso técnico son endógenos. La productividad no causa en primera instancia una mayor producción, más bien una mayor demanda por producto y una mayor producción para satisfacerla terminan incrementando a la larga la productividad y por ende la competitividad. ${ }^{7}$

El crecimiento para Kaldor es resultado de un proceso complejo de acción entre aumentos en la demanda inducidos por incrementos en la oferta, y de incrementos en la oferta generados como respuesta a los aumentos de la demanda. Desde el punto de vista de la demanda, los determinantes del crecimiento del producto manufacturero son al menos cuatro: el consumo, la inversión interna, la inversión externa y las exportaciones netas. Por el lado de la oferta existen dos tipos de restricciones: de insumos o de trabajo; Kaldor reconoció que el proceso de crecimiento económico es el resultado de una compleja interacción entre la oferta y la demanda, pero que en los países en vías de desarrollo los factores de demanda actuaban antes que los de la oferta.

De acuerdo con la estimación tradicional de la ley Verdoorn los cambios en la productividad laboral manufacturera son dependientes de los cambios en la producción manufacturera. La evidencia empírica sugiere que el coeficiente de dicha relación es alrededor de un valor de 0.5 , con lo que un incremento de la producción manufacturera del $10 \%$ termina incrementando la productividad laboral en 5\%; dicho coeficiente aporta información respecto a los rendimientos a escala.

Kaldor (1966), en el espíritu de Young (1928), concebía los rendimientos a escala como un fenómeno macroeconómico, relacionado con la interacción entre la elasticidad de la demanda y oferta por bienes manufacturados. Es esta fuerte y poderosa interacción la que da cuenta de la relación positiva entre el crecimiento del producto manufacturero y la productividad laboral (Thirlwall, 1983: 346$){ }^{8}$

La tercera ley de Kaldor propone que el crecimiento de la productividad agregada está positivamente relacionado con el crecimiento del producto

7 Un excelente resumen de la ley Verdoorn-Kaldor aparece en Bairam (1987). El nombre obedece a que la idea fue originalmente planteada por Verdoorn (1949) y retomada por Kaldor (1966).

8 Algunos trabajos que han evaluado esta ley para el caso mexicano son Ocegueda (2003), Calderón y Martínez (2005), Calderón (2008), Sánchez y Campos (2010) y Sánchez (2010). 
manufacturero y negativamente relacionado con el crecimiento del empleo no manufacturero. La lógica de esta relación es que un rápido crecimiento de las manufacturas incrementará la productividad manufacturera (y de aquí la productividad agregada) a través de la ley Verdoorn-Kaldor.

De hecho, con un excedente laboral en la agricultura y el sector servicios, un rápido crecimiento de las manufacturas aumentará el crecimiento de la productividad en este sector por los incrementos de las transferencias sectoriales de trabajo desde el resto de la economía a las manufacturas (como consecuencia del subempleo o desempleo disfrazado). Como el trabajo se mueve de la agricultura, donde la productividad marginal de trabajo es reducida, hacia las manufacturas donde ésta es alta, la productividad termina por incrementarse. De aquí se tiene que una rápida tasa de declive del empleo no manufacturero incrementará el crecimiento de la productividad no manufacturera.

Como resultado de los rendimientos crecientes en las manufacturas y del crecimiento de la productividad inducida en los sectores no manufactureros, se tiene que una rápida tasa de crecimiento del producto manufacturero conducirá a aumentar la tasa de crecimiento de la productividad de toda la economía.

Uniendo todas las proposiciones, se puede concluir que una rápida tasa de crecimiento del producto industrial manufacturero tenderá a establecer un proceso acumulativo o círculo virtuoso del crecimiento a través del enlace entre el crecimiento del producto y la productividad manufacturera. En caso contrario se establece un círculo vicioso de estancamiento o bajas tasas de crecimiento económico.

\section{ALGUNAS EXPLICACIONES SOBRE EL BAJO CRECIMIENTO ECONÓMICO EN MÉXICO}

El problema del bajo crecimiento económico en México ha sido objeto de múltiples interpretaciones, algunas de las cuales se exponen a continuación con la intención de destacar la contribución de la presente investigación.

Para Guillén (2000), la causa principal detrás del estancamiento se encuentra en las políticas que denomina neoliberales, las cuales siguen al pie de la letra los dictados del Consenso de Washington, sin considerar las particularidades y retos de la economía mexicana; en su opinión, tales políticas son de carácter procíclico, con lo que lejos de corregir el problema del bajo ritmo de crecimiento terminan profundizándolo. Siguiendo una línea de argumentación similar, Calva (2001) considera que la causa del problema se encuentra en la dependencia de la economía mexicana respecto al ciclo económico estadounidense, sumada a 
la estrategia macroeconómica recurrentemente aplicada en México desde tiempos de Salinas, que erige la estabilización de los precios en objetivo prioritario a ultranza.

Por otra parte, Fuji (2000) concluye que la causa básica del estancamiento proviene del sector externo. En los últimos 25 años, toda fase de crecimiento ha generado de modo sistemático un déficit en la balanza en cuenta corriente, que a la postre es imposible financiar con el ingreso de capitales. La alta elasticidad de las importaciones, rasgo tradicional de la economía, creció a raíz de la apertura externa. Ello se debió a que la industrialización por sustitución de importaciones redundó en una base industrial considerable, pero que en gran parte no podía competir con los productos importados, por lo que sobrevivía al amparo de la protección. El acelerado desmantelamiento de ésta no permitió que la mayoría de las empresas industriales se pusiera en posición de afrontar las nuevas condiciones de mercado. Así, los productos importados se apoderaron del mercado de bienes de consumo y, en particular, de intermedios y el de bienes de capital. Esta situación contribuyó a debilitar los encadenamientos entre las ramas de la manufactura, por lo que el crecimiento de la industria pasó a repercutir cada vez más directamente y en forma más que proporcional, en las importaciones manufactureras. Esto ha ocurrido tanto en las ramas exportadoras como en las orientadas al mercado interno. Para Huerta (2004), no se cuenta con el financiamiento interno para el crecimiento y los flujos externos se reducen al dejar de ofrecer la economía condiciones de rentabilidad. A lo que se suman las políticas monetarias y fiscales de carácter restrictivo. De acuerdo con Perrotini (2004), el régimen de inversión productiva insuficiente que prevalece desde la crisis de deuda externa, las políticas de ajuste, estabilización macroeconómica y cambio estructural en combinación con los vacíos institucionales de la economía mexicana, propiciaron un ambiente macroeconómico adverso para la inversión productiva y, por tanto, una reducción de la tasa de acumulación de capital. La resultante pérdida de empleo y producto es la inevitable contraparte del éxito de las políticas anti-inflacionarias.

Bajo un enfoque ortodoxo, Martínez et al. (2004) concluyen que la liberalización y el crecimiento han generado un mayor crecimiento e inversión; no obstante, la falta de reformas estructurales y la prolongada escasez de crédito han creado cuellos de botella que han bloqueado el mayor crecimiento y han llevado a la disminución reciente del crecimiento de las exportaciones.

Por su parte, Villarreal (2005) considera que al agotarse el modelo de industrialización por sustitución de importaciones el gobierno instrumentó un modelo de Apertura, Liberalización, Privatización y Estabilización (ALPES), que junto con un tipo de cambio real apreciado y políticas contraccionistas exacerbó el 
desequilibrio externo de la economía mexicana, que presiona a la baja la tasa de crecimiento económico.

Ros (2008) indica que el determinante del lento crecimiento de la economía mexicana es una baja tasa de inversión y cuatro factores la limitan: la reducida inversión pública, un tipo de cambio real apreciado desde 1990, el desmantelamiento de la política industrial durante el periodo de reforma y la falta de financiación bancaria. Ibarra (2008) apoya esta hipótesis al sostener que la desaceleración en el crecimiento se debe a la atonía de la inversión, como consecuencia de un tipo de cambio real sobrevaluado durante la desinflación, lo que se agrava por la merma a largo plazo de la razón PIB/capital.

De María y Campos et al. (2009) afirman, con base en un exhaustivo análisis histórico-estadístico, que el estancamiento prevaleciente obedece a las bajas tasas promedio de inversión y empleo en la economía nacional y en particular en el sector productivo; así como al comportamiento que tuvieron diversas políticas clave como son la fiscal, monetaria, de tipo de cambio, financiera y de apertura exterior, en el marco de un modelo que privilegia la estabilidad macroeconómica y los equilibrios fiscales. Pero también a la ausencia de estrategias y políticas apropiadas en las esferas sectorial (agropecuario, manufacturas y servicios) y regional.

Para Esquivel (2010), el establecimiento de reglas de conducción y comportamiento de la política macroeconómica ha ayudado a reducir la volatilidad y la inestabilidad macroeconómica, pero a costa de un menor crecimiento. La vinculación de la economía mexicana a la norteamericana, así como las políticas monetarias y fiscales procíclicas están dejando que el crecimiento de la producción esté sujeto a factores externos. En función de esto sugiere tener una política económica más activa y reducir la fuerte relación industrial entre México y los EE.UU.

Finalmente, Hanson (2010) considera que el bajo crecimiento económico es el resultado de la combinación de factores internos y externos. Entre los primeros señala la existencia de mercados de crédito que funcionan pobremente, la distorsión en la oferta de insumos no comerciables internacionalmente e incentivos a la informalidad. A nivel externo considera que el país tiene "mala suerte" al exportar bienes que China vende, en lugar de bienes que China compra."

9 La revisión de la literatura se hizo básicamente en revistas nacionales, pero en Kehoe y Ruhl (2010), el lector interesado puede encontrar la revisión de literatura internacional que explica la inestabilidad y el estancamiento de la economía mexicana posterior a la apertura. La mayor parte de autores internacionales coincide en que el bajo crecimiento se debe a instituciones financieras ineficientes, débil Estado de Derecho y rigideces en el mercado laboral. 


\section{BAJO CRECIMIENTO, (DES)EMPLEO E INSUFICIENCIA DINÁMICA MANUFACTURERA}

Después de una etapa de crecimiento sostenido, la economía mexicana vive desde principios de los ańos ochenta hasta la actualidad en un contexto macroeconómico de bajas tasas de crecimiento económico o estancamiento. Al graficar las tasas de crecimiento del PIB real mexicano se observa una tasa promedio anual del 0.09\% para el periodo 1982-1987; entre 1988-1993 creció a una tasa promedio anual del 3.14\%; para 1994-2000 creció al 2.91\% y finalmente para 2000-2010 su crecimiento fue del 1.30\% anual; para todo el periodo, 1982-2010, la economía apenas logró crecer un $2.1 \%$ promedio anual contra el 6.33\% conseguido entre 1940 y 1970.

La Gráfica 1 evidencia el estancamiento y bajo ritmo de crecimiento de largo plazo experimentado. ${ }^{10} \mathrm{~A}$ pesar de observarse un crecimiento significativo

Gráfica 1. Crecimiento anual del PIB real y promedios por periodo

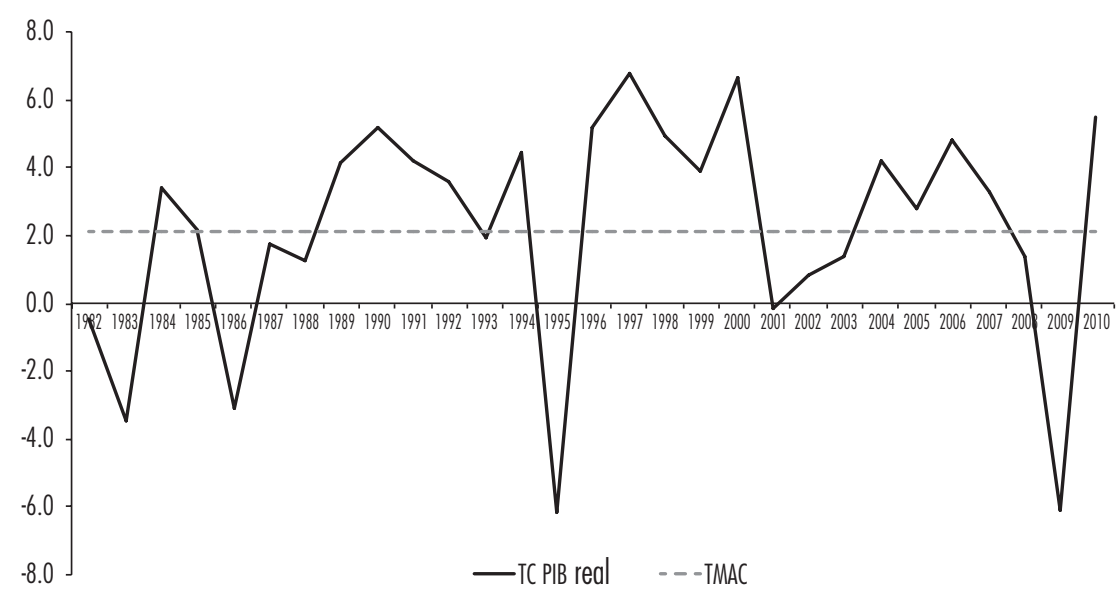

Fuente: elaboración propia con datos del INEGl.

10 De acuerdo con Moreno-Brid et al. (2006: 112), sostener una alta tasa de crecimiento económico en el largo plazo debe ser una prioridad en la agenda nacional. Si tomamos en cuenta que la mano de obra crece $2.5 \%$ en promedio al ańo, entonces la economía mexicana necesita crecer al menos a una tasa promedio anual de entre 5 y $6 \%$ en términos reales, apenas para crear los empleos que se demandan cada año. El crecimiento económico necesitaría ser incluso más fuerte si se quiere mejorar de manera perceptible el nivel de vida de más de 13 millones de mexicanos que viven en condiciones de extrema pobreza. 
para algunos años, la magnitud de las crisis y retrocesos sufridos redujeron los posibles impactos positivos de largo plazo, la economía crece y se detiene constantemente.

Parte de la explicación del bajo crecimiento del periodo obedece a situaciones coyunturales de origen externo y/o interno, como en los primeros años de los ochenta, o como sucedió recientemente con la crisis financiera mundial iniciada en el segundo semestre de 2008 en los Estados Unidos de Norteamérica. Sin embargo, la ralentización del crecimiento global, de acuerdo con el marco teórico expuesto en la primera parte, es de carácter estructural y está plenamente vinculada a la falta de vigor en el crecimiento de la producción manufacturera y a la ausencia de cualquier tipo de progreso técnico endógeno; son factores de carácter estructural los que impiden que la economía mexicana crezca al ritmo que debería.

De modo que el crecimiento económico del país ha sido totalmente insuficiente durante estas tres últimas décadas. Se observa en la Gráfica 1 cómo después de un periodo de estancamiento pleno, se recupera relativamente la estabilidad en el crecimiento de 1987 a 1994, aunque se mantiene la insuficiencia del mismo; después, de 1994 a 2000, aunque se crece notablemente en 1997 y en el último año, el crecimiento en promedio anual se reduce; dicha reducción continúa hasta el presente. Desde el 2001 se experimenta una nueva etapa de bajo crecimiento, muy parecida a la que prevalecía a principios de los ochenta. ${ }^{11}$

$\mathrm{Al}$ analizar las tasas de crecimiento del PIв per cápita, se observa una situación todavía peor; en el periodo 1982-1987 la economía decreció en términos reales $1.81 \%$ promedio anual, siendo 1982, 1983 y 1986 años terriblemente críticos, fueron retrocesos en el nivel de producción per cápita que con dificultad se recuperaron. Para el periodo 1988-1993 el crecimiento promedio anual del producto per cápita apenas fue $1.5 \%$ real, $1.64 \%$ de 1994 a 2000 y $0.42 \%$ de 2000 a 2010; de esta forma, de 1982 a 2010 el promedio anual de crecimiento fue $0.46 \%$, muy por debajo del presentado de 1940 a 1970 que fue $3.02 \%$.

Desde una perspectiva de largo plazo, claramente existe un proceso de estancamiento o bajas tasas de crecimiento del producto generado por la economía mexicana. Aunque también debe reconocerse la presencia de aumentos significativos en los ańos 1996, 1997, 1998, 2000 y 2006, los cuales resultan

11 En 2010 la economía creció 5.5\%, resultado de la recuperación de la abrupta caída del año anterior. En 2011 4.0\% y en 2012 se espera lo hiciera en 3.5\%; esto de acuerdo con estimaciones de la Secretaría de Hacienda. 
Gráfica 2. Evolución del ingreso per cápita en México, 1950-2010 (2010=100)

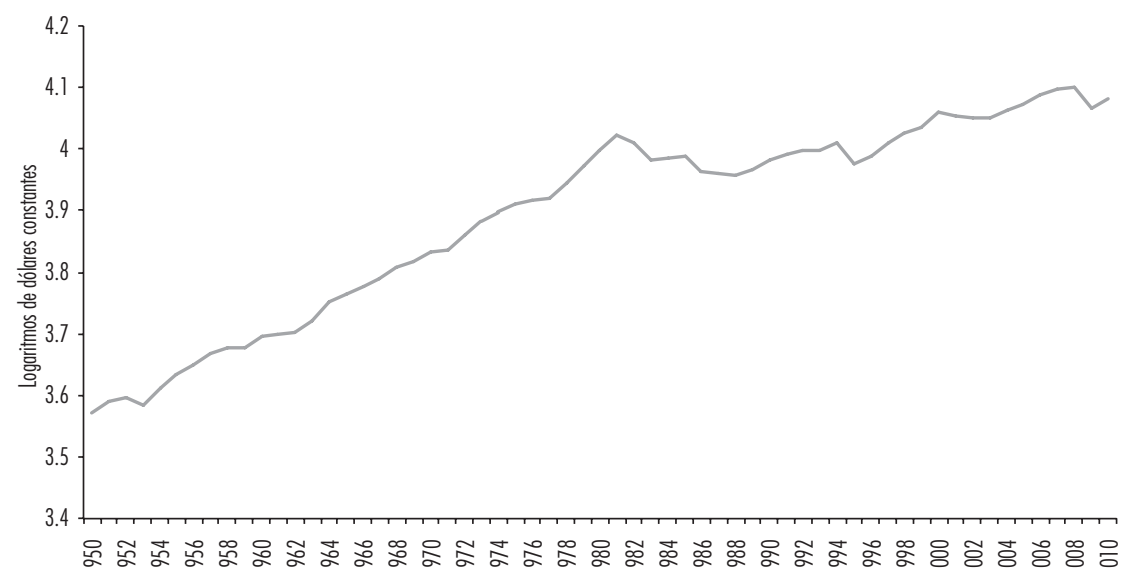

Fuente: elaboración con datos de The Conference Board.

insuficientes, ya que van siempre acompañados de reducciones de carácter crítico, sobre todo en 1995 y 2009. En casi treinta años la producción por persona ha estado estancada, particularmente si se le compara con lo ocurrido en los treinta ańos previos.

Siguiendo a Hausmann et al. (2005), se tiene que una economía experimenta una situación de crecimiento acelerado cuando el pIB per cápita supera el 3\% por lo menos durante un periodo de diez ańos. Por lo que cuando una economía no cumple con esta regla empírica se puede considerar que se encuentra en situación de bajo crecimiento.

Una secuencia ininterrumpida de crecimiento pobre o negativo es lo que aquí se interpreta como bajo crecimiento económico. Esto es precisamente lo que ha estado ocurriendo en la economía mexicana durante los últimos años. De especial relevancia es el periodo correspondiente a 1994-2010, ya que durante estos años, con la operación del Tratado de Libre Comercio (TLCAN), se consolida un modelo económico que privilegia la apertura y la estabilidad macroeconómica de corto plazo en detrimento del empleo y del crecimiento económico, variables que en el discurso se dice cuidar, pero que en la práctica se deprimen.

Las bajas tasas de crecimiento económico prevalecientes en el país han provocado que la economía nacional se rezague frente al resto del mundo, principalmente los Estados Unidos de Norteamérica, su principal socio comercial. 
Con datos de Moreno-Brid y Ros (2009: 261), se tiene que mientras en 1981 el PIB per cápita de México representaba 35.6\% del americano, para 2003 representaba $24.6 \%$, para 2005 el $25 \%$ y para 2009 el $22 \%$. La creciente divergencia económica entre los dos países es notoria; la razón sin duda es el bajo crecimiento económico en México.

En línea con lo expuesto en la primera parte, en el artículo se tiene un gran interés en el comportamiento de los diversos sectores de actividad económica, particularmente el manufacturero. La evolución del crecimiento económico sectorial se muestra en la Gráfica 3. Los datos revelan que durante el periodo 19822009 se observó una participación cada vez menor del sector agropecuario en el PIB total, de 6.3\% en 1982 pasó a 5.4\% en 2009; mientras tanto el sector industrial (incluye manufacturas, construcción y electricidad, gas y agua) pasó de $24.9 \%$ a $23.2 \%$, con lo que se contrajo cerca de dos puntos porcentuales; las manufacturas representaban 17\% del PIB en 1982 y 16\% en 2009; el sector de los servicios incrementó su participación al pasar de $62.7 \%$ a $65.9 \%$.

De 1982 a 1987 el decrecimiento del pIB per cápita fue de 1.8\%, el de la industria $0.59 \%$ y el de las manufacturas $0.11 \%$, mientras los servicios y el sector agropecuario crecieron $0.33 \%$ y $1.05 \%$ respectivamente. De 1988 a 1993 el crecimiento del pis per cápita fue de $1.5 \%$, el de la industria 3.44\%, manufacturas $3.54 \%$, servicios $3.30 \%$ y sector agropecuario $1.41 \%$. De 1994 a 2000,

Gráfica 3. Crecimiento anual por sector de actividad económica

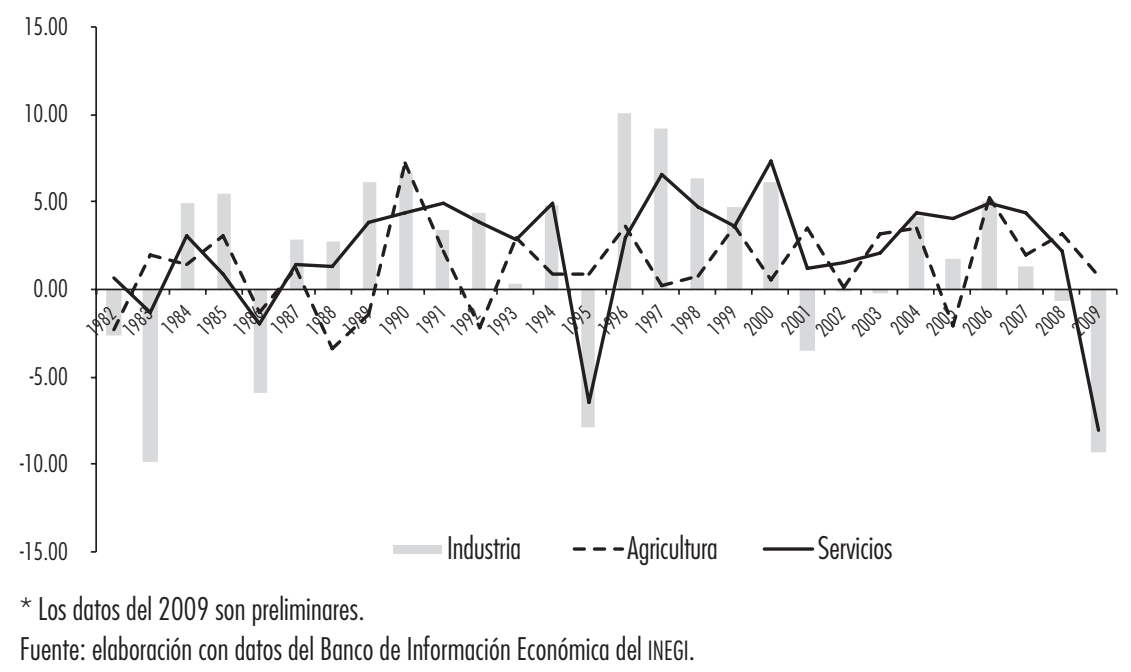


el PIB per cápita creció $1.6 \%$, industria 3.92\%, manufacturas $4.76 \%$, mientras los servicios crecieron $2.58 \%$ y el sector agropecuario $1.35 \%$. De 2000 a 2009 , el crecimiento del piB per cápita fue de apenas $0.42 \%$, la industria decreció $0.21 \%$, lo mismo las manufacturas en $0.96 \%$, mientras los servicios crecían $1.59 \%$ y el sector agropecuario $1.91 \%$.

Las manufacturas y la industria en general consiguen sus mejores tasas de crecimiento durante los subperiodos: 1988-1993 y 1994-2000, los mismos en los que el ritmo de crecimiento del PIB total y per cápita son más elevados; este resultado no es una coincidencia. Las manufacturas son un componente indispensable del crecimiento económico.

La economía mexicana se encuentra estancada, tanto en términos de PIB total como per cápita y junto a esto se observa un sector manufacturero que prácticamente no crece (insuficiencia dinámica) y un sector de servicios informales que se incrementa. ${ }^{12}$

En correspondencia con el marco teórico de referencia, se sabe que la mayor participación del comercio y los servicios, sin un aumento de la planta industrial, implica una reducción del crecimiento o bien un crecimiento temporal y ficticio, por la vía de una mayor dependencia de bienes de consumo, intermedios y de capital que tienen que ser importados para hacer frente a la creciente demanda; los servicios, a pesar de su relevancia, se supone no son el motor del crecimiento en México. ${ }^{13}$

Continuando, interesa insistir que los años en los que se presenta el mejor comportamiento del producto per cápita (1996-2000), son también los años en los que el pIB industrial manufacturero registra sus mayores tasas de crecimiento.

Existe una alta correlación entre el comportamiento del PIB industrial y el PIB total de la economía, el coeficiente de correlación entre las series es de 0.93,

12 De acuerdo con Samaniego (2008: 33), la economía informal presenta un crecimiento explosivo e indica que entre 2000 y 2005 pasó de 51.5 a 54.5\% de la población ocupada no agropecuaria. Agrega que en 2004 de los trabajadores del sector informal en México 44\% realizaba su actividad en su propio domicilio; generalmente en trabajo por cuenta propia, con la ayuda en ocasiones de trabajo familiar no remunerado; $19.8 \%$ poseía un micronegocio con local o vehículo en el que laboraba; $9 \%$ lo hacía como trabajadores ambulantes o en puestos improvisados, y $27.2 \%$ trabajaba como asalariados en empresas tanto del sector informal como del propio sector formal, pero carecían de todo tipo de prestaciones.

13 Existe toda una corriente de autores que opina lo contrario. Particularmente para el caso mexicano se recomienda la lectura de Garza y Sobrino (2009), en donde se hace un resumen de la importancia, estructura, dinámica y distribución geográfica del comercio y los servicios. 
Gráfica 4. Crecimiento anual de la manufactura, PIB total y per cápita

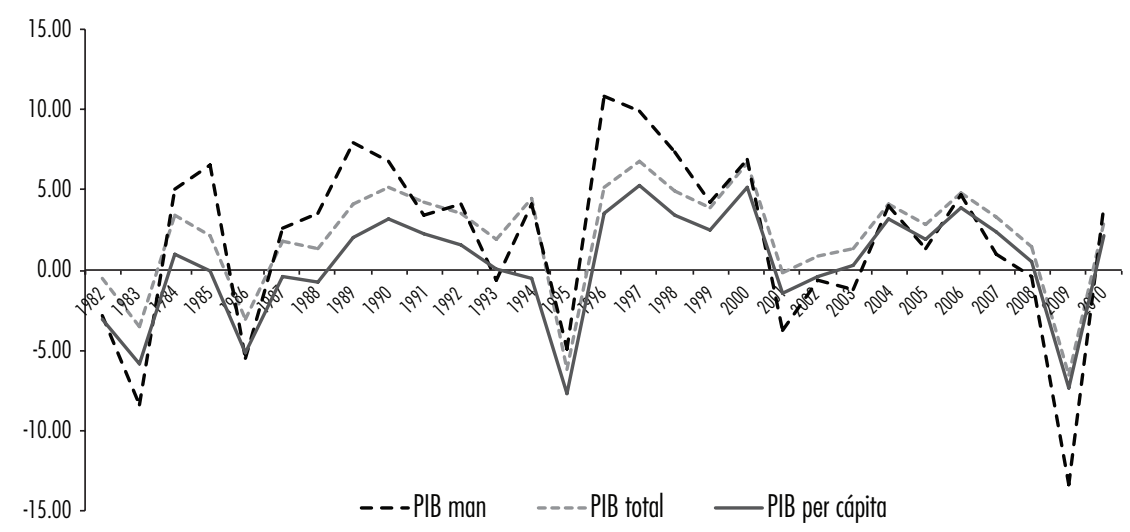

* Los datos a partir del 2009 son preliminares.

Fuente: elaboración con datos del Banco de Información Económica del INEGI.

lo que aporta evidencia preliminar de la importancia que tiene el sector industrial para el crecimiento o estancamiento económico del producto.

Al considerar exclusivamente al sector manufacturero y comparar sus tasas de crecimiento para el periodo 1982-2009 con las del crecimiento del producto total de la economía mexicana se encuentra un coeficiente de correlación de 0.88 .

Como era de esperarse por la primera ley de Kaldor, las manufacturas parecen regir una buena parte de la evolución económica del país. Dos años atípicos son 2002 y 2003, en los cuales el pIB manufacturero presentó valores negativos mientras el PIB total se incrementó ligeramente; previo a esto en 2001 la caída en el pIB manufacturero fue mucho mayor que la caída en el pIB total; un comportamiento semejante se observó en 1982, 1983, 1986, 1993 y 2009. La economía, en lo general, se mueve al ritmo que lo hacen las manufacturas, algo similar ocurre con la productividad (medida a través del pів per cápita).

De acuerdo con las cifras disponibles en el sistema de cuentas nacionales del INEGI, entre 1982 y 2009, el valor absoluto del producto generado en las manufacturas pasó de 173,609 millones de pesos reales a 287,694 millones de pesos, un incremento de $165 \%$ en 27 años; ${ }^{14}$ en términos anuales medios, las manufacturas crecieron $1.88 \%$ para todo el periodo, $-0.11 \%$ de 1982 a 1987, $3.54 \%$ de 1988 a

14 De 1940 a 1970 las manufacturas crecieron en términos absolutos un $840 \%$, con lo que para el periodo 1982-2009 se tiene una contracción relativa o desindustrialización. 
$1993,4.76 \%$ de 1994 a 2000 y -0.96\% de 2000 a 2009; confirmando que el periodo de mejor comportamiento del sector manufacturero coincide con el de mejor ritmo observado por el pIB total y per cápita de la economía.

Por otra parte, como resultado del bajo crecimiento de la producción, los empleos generados cada ańo desde 1982 al 2010 han sido insuficientes para cubrir la demanda; a pesar de los constantes discursos a favor de la creación de mayores empleos, los resultados demuestran que ningún gobierno del periodo bajo estudio ha podido satisfacer esta necesidad económica básica. En el Cuadro 1 se aprecia que incluso se han perdido empleos cada año en lugar de generarlos, así ha sido en 1982, 1986, 1995, 2001, 2003, 2008 y 2009 para el caso del sector privado y 1992, 1993, 2001, 2002, 2003 y 2005 para el sector público.

En promedio anual, de 1982 a 1987 se crearon 274,106 plazas en el sector privado y 152,793 en el sector público; en 1987-1993 se incrementó la creación en el sector privado pero se redujo drásticamente en el sector público; en 19942000 el promedio de empleos fue de 419,859 en el sector privado y 47,702 en el público; para el periodo 2000-2008 el empleo presenta un franco estancamiento al generarse en promedio 144,823 empleos cada ańo en el sector privado y 22,084 en el público, 166,907 empleos en todo el sector formal; la pregunta es ¿a dónde van a parar todos los mexicanos que se agregan anualmente a la población económicamente activa? Seguramente muchos de ellos engrosan las filas de la migración hacia los Estados Unidos de Norteamérica, otra parte se une a la economía informal, al subempleo y por supuesto se dedica a delinquir, en solitario o en grupos, organizada o desorganizadamente.

El Cuadro 1 también muestra cómo paulatinamente el sector público ha reducido las ofertas laborales, lo cual tiene diferentes interpretaciones, ya que por un lado es posible que esto redunde en una mayor eficiencia, pero por el otro significa que ante la pérdida de dinamismo del sector privado no existe en la economía formal mecanismo de compensación para los empleos necesarios, lo que conduce a la población directamente a la economía informal o la migración. ${ }^{15}$

Durante 2009, como resultado de la crisis financiera iniciada en los EE.UU., se perdieron más de 433 mil empleos en el sector privado, la mayoría de ellos en el sector manufacturero y de servicios, los cuales no fueron recuperados rápidamente; de hecho en 2010 apenas lograron crearse 323 mil empleos. Si a lo

15 Con datos de migración quinquenal del Conapo, se tiene que de 1987 a 1992 1,865,312 personas se fueron a trabajar a los Estados Unidos de América; de 1992 a 1997 fueron 1,952,459 y de 1997 al 2002 el número de migrantes fue 2,474,222. Mientras en 2001 había 24 millones de mexicanos en los EE.UU., en 2010 había 32.3 millones. 
Crecimiento económico y política industrial en México

Cuadro 1. Empleos generados anualmente

\begin{tabular}{|c|c|c|c|}
\hline Año & $\begin{array}{l}\text { Asegurados permanentes } \\
\text { del ImSS } \\
\text { (A) }\end{array}$ & $\begin{array}{c}\text { Sector público } \\
\text { (B) }\end{array}$ & $\begin{array}{c}\text { Empleo Formal } \\
\qquad(A+B)\end{array}$ \\
\hline 1982 & $-75,918$ & 211,636 & 135,718 \\
\hline 1983 & 22,583 & 274,856 & 297,439 \\
\hline 1984 & 571,274 & 243,076 & 814,350 \\
\hline 1985 & 501,793 & 105,858 & 607,651 \\
\hline 1986 & $-146,631$ & 51,984 & $-94,647$ \\
\hline 1987 & 771,536 & 29,347 & 800,883 \\
\hline 1988 & 159,962 & 279,014 & 438,976 \\
\hline 1989 & $1,009,280$ & 7,449 & $1,016,729$ \\
\hline 1990 & 837,676 & 22,927 & 860,603 \\
\hline 1991 & 520,000 & 28,724 & 548,724 \\
\hline 1992 & 55,000 & -178,443 & $-123,443$ \\
\hline 1993 & $-56,000$ & $-56,345$ & -112,345 \\
\hline 1994 & 245,000 & 80,367 & 325,367 \\
\hline 1995 & $-181,000$ & 37,786 & $-143,214$ \\
\hline 1996 & 804,000 & 31,317 & 835,317 \\
\hline 1997 & 882,000 & 100,643 & 982,643 \\
\hline 1998 & 303,504 & 77,795 & 381,299 \\
\hline 1999 & 488,071 & 3,976 & 492,047 \\
\hline 2000 & 397,439 & 2,031 & 399,470 \\
\hline 2001 & $-313,102$ & $-2,770$ & $-315,872$ \\
\hline 2002 & 19,372 & $-12,022$ & 7,350 \\
\hline 2003 & $-97,189$ & $-10,857$ & $-108,046$ \\
\hline 2004 & 227,466 & 64,555 & 292,021 \\
\hline 2005 & 184,954 & $-69,773$ & 115,180 \\
\hline 2006 & 478,365 & 84,193 & 562,558 \\
\hline 2007 & 465,432 & 67,978 & 533,410 \\
\hline 2008 & $-59,328$ & 75,424 & 16,096 \\
\hline 2009 & $-433,160$ & n.d. & - \\
\hline 2010 & 323,170 & n.d. & - \\
\hline promedio 1982-1987 & 274,106 & 152,793 & 426,899 \\
\hline promedio 1988-1993 & 420,986 & 18,953 & 348,207 \\
\hline promedio 1994-2000 & 419,859 & 47,702 & 467,561 \\
\hline promedio 2000-2008 & 144,823 & 22,084 & 166,907 \\
\hline
\end{tabular}

Fuente: elaboración con datos del IMSS e INEGI. 
anterior se le agrega el número de personas en edad de trabajar que cada año buscan un empleo, se encuentra un déficit estimado en el mercado laboral superior al millón de personas.

El empleo en México muestra una gran volatilidad y al igual que el crecimiento del producto es insuficiente para cubrir las necesidades de las personas que se agregan cada ańo al mercado de trabajo. Como resultado del estancamiento, el mercado laboral se encuentra deteriorado, lo que se asocia, entre otros factores, a la falta de crecimiento del sector manufacturero. ${ }^{16}$

La creciente precarización del empleo, sobre todo en los últimos diez ańos, se exhibe en el Cuadro 3; mientras en 2000 la población ocupada en el sector informal y subocupada (empleo precario) era de más de 13 millones de personas, para 2010 se estima en poco más de 19 millones de personas, de las cuales 518,448 se encontraban subocupadas en el sector manufacturero; la subocupación en ese sector pasó de representar el $20.9 \%$ del total en 2000 , al $13.1 \%$ en 2010. Lo que las cifras demuestran es la existencia de un proceso más allá del estancamiento en materia de empleo, una etapa crítica de desempleo, subocupación e informalidad. ${ }^{17}$

Cuadro 2. Perspectiva del des (empleo) en México

\begin{tabular}{cccc}
\hline Año & $\begin{array}{c}\text { Nuevos buscadores } \\
\text { de emplea }^{a}\end{array}$ & $\begin{array}{c}\text { Empleos si sigue } \\
\text { la tendencia }\end{array}$ & $\begin{array}{c}\text { Empleos si la economía } \\
\text { creciera más rápido }^{c}\end{array}$ \\
\hline 2010 & 987,911 & 572,865 & 981,167 \\
2011 & 957,535 & 584,982 & $1,023,218$ \\
2012 & 921,020 & 597,437 & $1,067,372$ \\
Total & $2,866,466$ & $1,755,284$ & $3,071,757$ \\
\hline
\end{tabular}

Fuente: elaboración con base en Peralta (2007: 208).

a Proyectados por el CONAPO

${ }^{\mathrm{b}}$ Crecimiento de 2.8\%

'Más rápido implica 5\%

16 De acuerdo con el Imss, en julio de 2011 se encontraban registrados 15 millones de trabajadores formales, con lo que sólo una tercera parte de los ocupados en este país gozan de los servicios sociales que dicha institución ofrece. El poco empleo que se genera resulta ser de mala calidad y no contribuye al fortalecimiento del mercado interno para iniciar un círculo virtuoso de acumulación.

17 De acuerdo con el INEGI, al segundo trimestre de 2011 existían en el país 13,385,674 mexicanos ocupados en el sector informal. Para Murayama (2012), el INEGI subestima a la informalidad y considera que en 2010 el empleo informal alcanzó los 26 millones de personas, 59\% de la población ocupada. 
A partir de los datos se verifica que existe en México desde hace poco más de un cuarto de siglo un marcado proceso de estancamiento, o para ser más precisos, bajas tasas de crecimiento que se traducen en una insuficiente capacidad de generación de empleos, ante una creciente demanda del mismo dado el crecimiento poblacional. La insuficiencia dinámica ha provocado una reducción en el bienestar de millones de mexicanos. ${ }^{18}$

Los resultados económicos obtenidos durante los últimos veintinueve años dan cuenta de la catástrofe. De 1982 a 2010 el PIB total creció un $2.1 \%$ promedio anual; el PIB per cápita $0.46 \%$; entre 1982 y 2008 se creó un promedio anual de 354,306 empleos en el sector formal de la economía; la tasa de

Cuadro 3. Precarización del empleo en México

\begin{tabular}{rcccll}
\hline Año & POI & POS & POS man & POS man (\% del total) & Empleo precario \\
\hline 2000 & $10,354,145$ & $2,732,650$ & 571,085 & 20.9 & $13,086,795$ \\
2001 & $10,642,961$ & $2,534,235$ & 463,332 & 18.3 & $13,177,196$ \\
2002 & $11,037,333$ & $2,674,653$ & 475,250 & 17.8 & $13,711,986$ \\
2003 & $11,456,603$ & $3,150,604$ & 536,074 & 17.0 & $14,607,207$ \\
2004 & $11,540,197$ & $3,105,265$ & 451,662 & 14.5 & $14,645,462$ \\
2005 & $11,626,576$ & $2,831,865$ & 381,161 & 13.5 & $14,458,441$ \\
2006 & $11,421,546$ & $3,074,226$ & 438,006 & 14.2 & $14,495,772$ \\
2007 & $11,766,106$ & $2,992,806$ & 423,013 & 14.1 & $14,758,912$ \\
2008 & $11,857,285$ & $3,014,899$ & 414,613 & 13.8 & $14,872,184$ \\
2009 & $12,319,602$ & $3,996,792$ & 594,080 & 14.8 & $16,251,089$ \\
2010 & $12,587,956$ & $3,953,555$ & 518,4448 & 13.1 & $19,590,111$ \\
\hline
\end{tabular}

POl: población en el sector informal; POS: población subocupada y POS man: subocupada en las manufacturas.

Fuente: elaboración con datos del Banco de Información Económica del INEGl.

18 Con cifras del Consejo Nacional de Evaluación de la Política Social (Coneval), en 2010 existían 52 millones de personas pobres, de las cuales 11.7 eran consideradas indigentes. Las cifras muestran un incremento respecto a 2008, cuando se tenían 48.8 millones de personas pobres. Es importante mencionar que más de 38 millones de personas en 2010 eran vulnerables por ingresos y por carencias sociales; únicamente 21.8 millones de mexicanos eran considerados no pobres. 
crecimiento del pIB manufacturero de 1982 a 2009 fue $1.88 \%$ promedio anual. Finalmente, el empleo precario pasó de más de 13 millones de seres humanos a poco más de 19 millones. ${ }^{19}$

\section{POLÍTICA INDUSTRIAL EN MÉXICO?20}

\section{Los principios del Consenso de Washington y la política industrial en México}

Desde mediados de los ochenta la economía mexicana opera bajo un modelo económico liberal ortodoxo, cuyas políticas económicas se profundizan en los años noventa con los principios del Consenso de Washington. ${ }^{21}$ Este modelo económico está sustentado en dos pilares fundamentales: la estabilización macroeconómica antiinflacionaria del corto plazo y la liberalización indiscriminada del comercio internacional y de los flujos de capital.

19 En el marco del modelo económico vigente, las altas tasas de desempleo o el subempleo se interpretan como el resultado de la existencia de rigideces o falta de incentivos para adaptarse a los cambios en la economía internacional. La flexibilidad es la meta y la desregulación es la prescripción tradicional en este enfoque de oferta. Los factores que son cuestionados abarcan distintas variables. Los salarios están por encima de su precio de equilibrio afectando el nivel de empleo, mientras que la reducción de los diferenciales limita la movilidad y los incentivos para adquirir nuevas capacidades. La menor movilidad determinada por la falta de incentivos y por las restricciones legales impide el ajuste estructural, eleva los costos del trabajo y reduce su eficacia. Por último, las regulaciones introducidas para proteger la estabilidad y el ingreso de los trabajadores son también interpretadas como elementos de rigidez al encarecer los costos y constituir salarios de reserva por debajo de los cuales no existen incentivos para aceptar empleo (Tokman, 1991: 185).

Dos textos que ayudan a entender la importancia de la política industrial son Saboniené (2010) y UNCTAD (2007). El primero discute las contradicciones de la política industrial en el contexto de la integración económica y las posiciones a favor y en contra del uso de la misma como instrumento para lograr un mayor crecimiento económico. El segundo presenta argumentos a favor de la política industrial y define sus dominios.

21 El Consenso de Washington fue desarrollado originalmente por John Williamson en noviembre de 1989 en "What Washington Means by Policy Reform", y sus principios generales son los siguientes: 1) Disciplina fiscal; 2) Reordenamiento del gasto, es decir, debe de concentrarse donde sea más rentable; 3) Reforma impositiva: ampliación de las bases de los impuestos y reducción de los impuestos más altos; 4) Liberalización de los tipos de interés; 5) Tipo de cambio flexible y competitivo; 6) Liberalización del comercio internacional; 7) Liberalización de los flujos de capital (de corto y largo plazo); 8) Privatización; 9) Desregulación de los mercados; 10) Protección de la propiedad privada; y 11) Privatización de los servicios públicos de salud y educación. 
A raíz de la firma del Tratado de Libre Comercio de América del Norte (TLCAN), la industria maquiladora de exportación (IME) y el comercio intraindustrial recibieron un impulso que llegó a su fin con la aparición de la recesión estadounidense de 2000-2001. La apertura indiscriminada y el impulso al comercio intra-industrial trajeron consigo la desarticulación de las cadenas productivas y un menor crecimiento en el país. Con la recesión la IME y las exportaciones comenzaron a estancarse, lo que puso en evidencia las fragilidades del sector exportador y la mayor dependencia de México de la economía norteamericana. ${ }^{22}$

La política macroeconómica de corto plazo logró contener la inflación en niveles menores a un dígito, a costa de mantener el tipo de cambio peso-dólar apreciado, con pobres resultados en términos de promoción de las exportaciones y de empleo. La principal falla del modelo económico ortodoxo liberal mexicano radica en su incapacidad estructural para generar crecimiento económico, principalmente en el sector industrial-manufacturero, y por ende en su imposibilidad por generar empleo y aumentar la productividad. Esto se explica también por las políticas comerciales e industriales que se aplicaron durante el periodo, basadas exclusivamente en criterios de eficiencia del mercado y de cálculos de coste-beneficio, para eliminar las llamadas distorsiones de mercado. Las políticas comerciales e industriales aplicadas por todos estos gobiernos, desde Salinas de Gortari hasta Felipe Calderón, han sido pasivas y han tenido como único objetivo abolir todas las barreras que no permiten la asignación eficiente de los recursos en los mercados, en el marco de una economía de "libre mercado". Estas políticas han buscado eliminar todas las regulaciones del Estado, los monopolios de Estado, los monopolios privados, los aranceles, etcétera, bajo un escenario de competencia global en los mercados. Todos estos gobiernos neoliberales rechazaron la idea de la industrialización como base del desarrollo económico, renunciando así al gran objetivo del desarrollo económico para México. Todos adoptaron una política comercial e industrial pasiva que dejaba simplemente el desarrollo de la industria manufacturera en manos del "libre juego" de las fuerzas del mercado.

22 De acuerdo con María y Campos et al. (2009) el modelo exportador manufacturero mexicano actual tiene las siguientes fallas: 1) desintegración de las cadenas productivas; 2) desplazamiento del capital nacional en los sectores más dinámicos por la IED; 3) concentración de mercado y rezago de la PyмE; 4) financiamiento insuficiente; 5) rezago en la infraestructura y el gasto en tecnología; y 6) deficiencias en la infraestructura de telecomunicaciones. 
Estos gobiernos han permitido que sean las "fuerzas del mercado", en un contexto de mundialización, globalización e integración económica regional, las que decidan qué empresas subsisten y cuáles desaparecen; una "libertad" engañosa y discrecional es la que decide el futuro industrial del país. ${ }^{23}$ Ya no es el Estado nacional el que lleva el rumbo económico del país, sino es el mercado mundial el que decide de manera ciega la asignación de los segmentos de la industria que se van a localizar en nuestro territorio nacional. De manera que mientras el Estado mexicano esté subsumido a la lógica del mercado global, éste será incapaz de implementar políticas comerciales e industriales activas, promotoras del desarrollo económico. El bajo crecimiento económico que enfrenta la economía mexicana desde hace 24 años es el resultado de una industria manufacturera que no crece adecuadamente. ${ }^{24}$

Durante los últimos 29 ańos pueden distinguirse dos etapas contrastantes: 1) 1982 a 1993 es una etapa de desarrollo económico trunco, en la que todavía se aplicaron políticas industriales activas que enfatizaron en la necesidad de un cambio estructural hacia una mayor apertura exterior y la promoción selectiva y condicionada de ramas y regiones industriales prioritarias (con el PRONA$\mathrm{CIFE}^{25}$ y el PROFIEX ${ }^{26}$ ); desafortunadamente escasearon los recursos para llevarlas a cabo y algunas políticas macroeconómicas operaron en su contra; y 2) 1993 a 2005, cuando la política industrial activa desaparece, y se implementa el TLCAN,

23 En este punto es importante comparar la trayectoria industrial de México con la de otros países latinoamericanos, en aras de obtener una mejor evaluación de resultados. Los autores estamos trabajando en esa dirección y recomendamos revisar los trabajos de Kupfer et al. (2009) para el caso de Brasil, y Azpiazu y Schorr (2011) para el caso de Argentina.

24 Al hablar de México hablamos de un país que dejó virtualmente de crecer, y que también ha ido acumulando viejas distorsiones sociales que no se han podido eliminar (Pipitone, 1994: 391). Un país en el cual $40 \%$ de las familias más pobres absorbe $14 \%$ del ingreso nacional frente a $52 \%$ que se apropia el $20 \%$ de las familias más ricas. Un país plagado de problemas estructurales como la informalidad, la agricultura de subsistencia, la corrupción, la herencia colonial, etcétera.

25 Programa Nacional de Fomento Industrial y Comercio Exterior que fue promulgado el 31 de julio de 1984 como programa sectorial del ejecutivo federal en el marco del Plan Nacional de Desarrollo. Es un programa interesante que plantea fortalecer al mercado interno, aumentar la integración y eficiencia de la planta nacional con el objetivo de hacer frente a una economía mundial en constante cambio.

26 Programa de Fomento Integral a las Exportaciones que apareció durante los meses de marzoabril de 2005 . 
que dio un fuerte impulso a las maquiladoras, al comercio intra-industrial y a la inversión extranjera. ${ }^{27}$

De 1993 a la fecha, el principal instrumento utilizado por las autoridades para fomentar a la industria ha consistido en la promoción de la apertura comercial y la firma de tratados comerciales, en el entendido de que el Estado debe retirarse de la actividad económica y únicamente crear las condiciones para una operación eficiente del mercado eliminando todo tipo de distorsión. ${ }^{28}$

La nueva política industrial tiene como objetivo central lograr un funcionamiento eficiente de los mercados y fomentar la competencia, ya que se cree que éste es el mejor camino para que la iniciativa privada tome decisiones en términos de inversión, producción y empleo. A raíz de las reformas estructurales y la firma del TLCAN, el Estado mexicano dejó de cumplir con su papel de promotor del desarrollo económico. La acción del Estado se redujo a crear las condiciones para el funcionamiento "eficiente" del mercado mediante la desregulación, desprotección, privatización, reglas, derechos de propiedad privada e infraestructura física y humana. Lo anterior no es del todo negativo, ya que se reconoce que el Estado tiene fallas, pero también tiene que advertirse que el mercado las tiene. Pero más allá de eso, se tiene que reconocer que México es una economía en vías de desarrollo que requiere de una política industrial activa como base de un nuevo modelo de desarrollo económico. ${ }^{29}$

27 Para un análisis completo de la política industrial durante el periodo 1988-1994 revise Clavijo y Casar (1994), especialmente el capítulo 1 del tomo I. También revise Máttar y Peres (1997), donde se analiza el Programa Nacional de Modernización Industrial y del Comercio Exterior, 1990-1994 y el Programa de Política Industrial y Comercio Exterior de 1996. En Dussel (1997) se presenta un análisis del sector manufacturero mexicano y de la política industrial implementada desde 1982 a 1994.

28 En Ramos (1997) se encuentra un excelente balance de las reformas liberales en América Latina. Para el caso de México describe la política comercial y macroeconómica de 1985 a 1995. En su opinión las reformas liberales fueron parcialmente exitosas en áreas como la apertura comercial, la reforma al sistema de pensiones y la reforma tributaria. Las más costosas han sido las políticas anti-inflacionarias y la liberalización financiera.

29 Rodrik (2008) aclara este punto al señalar que el modelo correcto de política industrial no consiste en un gobierno autónomo que aplica impuestos o subsidios piguvianos, sino en una colaboración estratégica entre el sector privado y el gobierno con la meta de descubrir los principales obstáculos a la reestructuración productiva y el tipo de intervenciones que tienen que ser removidas. La tarea de la política industrial consiste en obtener información del sector privado sobre las externalidades que son importantes y sus remedios, para aplicar medidas que sean pertinentes, contribuir a una mayor eficiencia. 


\section{Trayectoria industrial en México 2006-2012}

La política comercial e industrial aplicada por el gobierno de Felipe Calderón sigue los mismos preceptos ortodoxos y liberales de los gobiernos que lo precedieron. Ha aplicado una política pasiva que busca eliminar las distorsiones del mercado, en base a los principios del libre mercado y que está fundada en el análisis costo beneficio. $\mathrm{Y}$ al igual que sus predecesores rechaza el gran objetivo de la industrialización como fundamento del desarrollo económico. Sin embargo, el gobierno de Felipe Calderón ha adoptado y defendido los principios del Consenso de Washington, y de la economía ultra-liberal, de manera más radical que sus predecesores.

De acuerdo con la Secretaría de Economía, la política industrial y comercial del gobierno actual se propone fundamentalmente resolver las distorsiones de mercado tales como las externalidades, los monopolios u oligopolios, los mercados incompletos, la información asimétrica y de coordinación de los agentes.

Ahora bien, estos principios económicos liberales se articulan en una serie de programas de fomento a la industria, tanto de carácter horizontal como vertical, que buscan fortalecer sobre todo a la Inversión Extranjera Directa (IED). Existen cuatro grupos diferenciables de políticas de atracción de la IED: el primer tipo de políticas aplicadas combina la protección, incentivos financieros y fiscales para promover la localización de las trasnacionales en sectores nuevos y estratégicos; ejemplo de esto es el apoyo a la industria automotriz y la "naciente" industria aeronáutica. ${ }^{30} \mathrm{El}$ segundo tipo de políticas consiste en un número de medidas originalmente dirigidas a sectores específicos. Éste es el caso de los apoyos para la localización de las trasnacionales de la industria de la electrónica, software y computación. El tercer tipo de políticas orientadas a las actividades altamente concentradas que muestran grandes economías de escala y redes, tales como la electricidad, telecomunicaciones, petróleo y gas natural. En el caso

30 En México las trasnacionales producen automóviles desde hace 85 años, y últimamente el gobierno ha aplicado instrumentos para que se implanten las maquilas y las compañías trasnacionales de la aeronáutica en el territorio nacional. De este modo el gobierno favorece el comercio intra-industrial de la aeronáutica. Hasta ahora lo que se ha impulsado es la maquila en este sector. De acuerdo con datos de la Federación Mexicana de la Industria Aeroespacial, en 2011 sus exportaciones intra-industriales crecieron $28 \%$ con respecto a 2010; las inversiones realizadas en el sector (sobre todo extranjeras) fueron de 4 mil 200 millones de dólares desde 2009. Hoy en día esta industria cuenta con 238 empresas, genera 37 mil empleos y sólo el $30 \%$ de sus exportaciones intra-industriales son de contenido nacional. 
mexicano, la mayor parte de estos sectores está en manos del Estado, excepto las telecomunicaciones. En el caso de estas últimas, el apoyo gubernamental básicamente consiste en desarrollar marcos regulatorios flexibles, que faciliten la creación y fortalecimiento de las agencias de competencia. Y con el pretexto de impulsar la competencia, el gobierno busca privatizar y eliminar lo que denomina distorsiones en el sector, contraviniendo los principios mismos de nuestra Carta Magna especificados en el Artículo 27.

El cuarto tipo de políticas territoriales de medidas de apoyo a los llamados clústeres, particularmente empresas de tamańo pequeño y mediano, o actividades en las cuales opera un elevado número de pequeñas firmas básicamente bajo el liderazgo de grandes compañías trasnacionales. ${ }^{31}$

\section{CONCLUSIONES}

La economía mexicana está por cumplir treinta años de bajo crecimiento en promedio anual; durante el periodo que va de 1982 a 2010 apenas ha crecido un $2.1 \%$, muy por debajo de lo alcanzado durante la etapa del desarrollo estabilizador o la etapa de crecimiento compartido. A nivel de PIB per cápita las cosas están todavía peor, ya que en el mismo lapso se registra un crecimiento de $0.46 \%$ medio anual. Asociado con este magro crecimiento económico se encuentra el elevado desempleo y la precarización del empleo: entre 1982 y 2008 apenas se crearon 354,306 empleos en promedio anual en el sector formal de la economía, y entre 2000 y 2010 el número de empleos precarios se incrementó en más de seis millones de personas.

Existen dos causas posibles de este decepcionante desempeño económico. La primera tiene que ver con la incapacidad de la economía nacional para hacerse de un núcleo endógeno de dinamización tecnológica en el sector manufacturero; la industrialización nunca se completó, lo que generó una deficiencia estructural que impide crecer más allá de ciertos límites, las manufacturas han reducido su tasa de crecimiento y con ello han mermado la productividad y por ende el crecimiento global. La segunda tiene que ver con las reformas estructurales liberales aplicadas a mediados de los ochenta, ante el agotamiento del viejo modelo económico basado en el Estado y la industria como motor del

31 Respecto a este tema existe una vasta literatura, pero una buena síntesis para América Latina y México se encuentra en Altenburg y Meyer-Stamer (1999); un ejemplo de este tipo de política para el caso mexicano se presenta en Hualde y Gomis (2007). 
crecimiento; estas reformas representaron un viraje hacia una economía de mercado y una política comercial e industrial pasiva cuyo objetivo único era la abolición de las distorsiones del mercado que han dañado seriamente la capacidad potencial de crecimiento del país.

El fracaso de la política comercial e industrial de los gobiernos liberales, desde Carlos Salinas hasta Felipe Calderón, resulta evidente porque no han logrado impulsar el crecimiento económico ni el empleo que necesita el país para mantener el bienestar de la población. Estos gobiernos abandonaron la idea del Estado y la política comercial e industrial activa como palancas del desarrollo económico.

Por lo que para impulsar el crecimiento de la economía mexicana no tan sólo se requiere la aplicación de una política comercial e industrial estratégica que impulse el crecimiento de manera activa, sino que esta política deberá de darse en el marco de una política económica más amplia que promueva el desarrollo económico de México. Es decir que promueva un cambio estructural cuyo objetivo sea: mejorar los niveles de ingreso, superar los grandes diferenciales en los ingresos entre regiones y sectores al interior del país, y por ende eliminar el dualismo económico.

El reto reside en construir un nuevo modelo de desarrollo económico, donde el sector industrial tenga un rol estratégico, principalmente las manufacturas, como eje articulador del sano desempeño de la economía. Se requiere un nuevo modelo de desarrollo económico que conduzca al país, primero a reparar los daños del modelo actual y después a retomar la senda del crecimiento económico sostenido. La nueva política comercial e industrial activa como palanca del desarrollo económico, debe reconocer la importancia que tiene el mercado para la asignación de los recursos, pero también al Estado como promotor del desarrollo económico.

\section{BIBLIOGRAFÍA}

Altenburg, Tilman y Jörg Meyer-Stamer, "How to Promote Clusters: Policy Experiences from Latin America”, en World Development, vol. 27, num. 9.

Azpiazu, Daniel y Martín Schorr, "La industria argentina en las últimas décadas: una mirada estructural a partir de los datos censales", en Realidad Económica, núm. 259, Buenos Aires, Instituto Argentino para el Desarrollo Económico, 2011, pp. 12-41.

Bairam, Erkin, "The Verdoorn Law, Returns to Scale and Industrial Growth: a Review of the Literature", en Australian Economic Papers, vol. 26, num. 48, Australia, Wiley-Blackwell, 1987, pp. 20-42. 
Boltvinik, Julio y Enrique Hernández, "Origen de la crisis industrial: el agotamiento del modelo de sustitución de importaciones. Un análisis preliminar", en Cordera, Rolando (comp.), Desarrollo y crisis de la economía mexicana, Colección Lecturas del Trimestre Económico, México, Fondo de Cultura Económica, 1981, núm. 39.

Calderón, Cuauhtémoc y Gerardo Martínez, "La ley de Verdoorn y la industria manufacturera regional en México en la era del TLCAN", en Frontera Norte, vol. 17, núm. 34, Tijuana, El Colef, 2005, pp. 103-137.

Calderón, Cuauhtémoc, "Crecimiento y rendimientos crecientes a escala en la industria manufacturera regional mexicana", en Martínez, Trinidad (coord.), Desarrollo regional en México, México, Universidad Autónoma Metropolitana, Unidad Azcapotzalco, 2008, pp. 45-75.

Calva, José Luis, "La economía mexicana en recesión", en Problemas del Desarrollo, vol. 32, núm. 126, México, Instituto de Investigaciones Económicas-UnAM, 2001, pp. 237-252.

Chang, Ha-Joon, The Political Economy of Industrial Policy, Londres, Macmillan, 1994.

Clavijo Fernando y José Casar, La industria mexicana en el mercado mundial. Elementos para una politica industrial, México, Fondo de Cultura Económica, 1994.

Concamin, México: La ruta del progreso, México, Confederación de Cámaras Industriales, 2012.

De María y Campos, Mauricio, Necesidad de una nueva politica industrial para el México del siglo XXI, México, Centro Lindavista, 1999.

De María y Campos, Mauricio, Lilia Domínguez, Flor Brown y Armando Sánchez, El desarrollo de la industria mexicana en su encrucijada, México, Universidad Iberoamericana de la Ciudad de México e Instituto de Investigaciones sobre Desarrollo Sustentable y Equidad Social, 2009.

Dussel, Enrique, La economía de la polarización. Teoría y evolución del cambio estructural de las manufacturas mexicanas (1988-1996), México, Editorial jus, 1997.

Esquivel, Gerardo, "De la inestabilidad macroeconómica al estancamiento estabilizador: el papel del diseño y la conducción de la política económica”, en Lustig, Nora (coord.), Crecimiento económico y equidad, México, El Colegio de México, 2010, pp. 35-78.

Femia, Presentación de la industria aeroespacial en México, México, Federación Mexicana de la Industria Aeroespacial, 2012.

Fuji, Gerardo, "El comercio exterior manufacturero y los límites al crecimiento económico de México", en Comercio Exterior, vol. 50, núm. 11, México, Bancomext, 2000, pp. 1008-1014. 
Garza, Gustavo y Jaime Sobrino (coords.), Evolución del sector servicios en ciudades y regiones de México, México, El Colegio de México, 2009.

Guillén, Arturo, México hacia el siglo XXI. Crisis y modelo económico alternativo, México, Plaza y Valdés Editores y uaM, 2000.

Hanson, Gordon, "Why isn't Mexico Rich?", en Journal of Economic Literature, vol. 48, num. 4, Pittsburg, AEA, 2010, pp. 987-1004.

Hausmann, Ricardo, Lant Pritchett y Dani Rodrik, "Growth Accelerations", en Journal of Economic Growth, vol. 10, num. 4, Holanda, Springer, 2005, pp. 303-329.

Hualde, Alfredo y Redi Gomis, "Pyme de software en la frontera norte de México: desarrollo empresarial y construcción institucional de un cluster", en Problemas del Desarrollo, vol. 38, núm. 50, México, Instituto de Investigaciones Económicas-UnAM, 2007, pp. 193-212.

Huerta, Arturo, La economía política del estancamiento, México, Diana, 2004.

Ibarra, Carlos, "La paradoja del crecimiento lento de México", en Revista de la CEPAL, núm. 95, Chile, CEPAL, 2008, pp. 83-102.

Kaldor, Nicholas, Causes of the Slow Rate of Economic Growth of the United Kingdom: an Inaugural Lecture, Londres, Cambridge University Press, 1966.

Kehoe, Timothy y Kim Ruhl, "Why have Economic Reforms in Mexico not Generated Growth?”, en Journal of Economic Literature, vol. 48, num. 4, Pittsburg, AEA, 2010, pp. 1005-1027.

Kupfer, David, Joao Ferraz y Laura Carvalho, "50 años en 50. El largo y sinuoso camino del desarrollo industrial de Brasil", en Boletín Informativo Techint, núm. 330, Buenos Aires, Cámara de Exportadores de la República de Argentina, 2009, pp. 45-72.

Loría, Eduardo, "Sobre el lento crecimiento económico de México. Una explicación estructural”, en Investigación Económica, vol. 68, núm. 270, México, UNAM, 2009, pp. 36-68.

Martínez del Campo, Manuel, Industrialización en México. Hacia un análisis crítico, México, El Colegio de México, 1985.

Martínez, Lorenza, Aarón Tornell y Frank Westermann, "Globalización, crecimiento y crisis financieras. Lecciones de México y del mundo en desarrollo", en Trimestre Económico, vol. 71, núm. 282, México, FCE, 2004, pp. 251-351.

Máttar Jorge y Wilson Peres, "La política industrial y de comercio exterior en México", en Peres, Wilson (coord.), Politicas de competitividad industrial. América Latina y El Caribe en los años noventa, México, Siglo xxi Editores, 1997, pp. 219-261.

Moreno-Brid, Juan Carlos, Jesús Santamaría y Juan Rivas Valdivia, "Manufactura y TLCAN: un camino de luces y sombras", en Economía UNAM, vol. 3, núm. 8, México, unAm, 2006, pp. 95-114. 
Moreno-Brid, Juan Carlos y Jaime Ros, Development and Growth in the Mexican Economy: a Historical Perspective, Nueva York, Oxford University Press, 2009.

Murayama, Ciro, "Informalidad laboral: la dimensión real", en El Universal, 12 de febrero, 2012.

Ocegueda, Juan Manuel, "Análisis kaldoriano del crecimiento económico de los estados de México, 1980-2000”, en Comercio Exterior, vol. 53, núm 11, México, Bancomext, 2003, pp. 1024-1034.

Peralta, Ernesto, “2006-2010: ¿el sexenio del empleo?”, en Frontera Norte, vol. 19, núm. 37, Tijuana, El Colef, 2007, pp. 203-209.

Peres, Wilson, The Slow Comeback of Industrial Policies in Latin America, Santiago de Chile, CEPAL, 2006.

Peres Wilson y Annalisa Primi, Theory and Practice of Industrial Policy. Evidence from the Latin America Experience, Santiago de Chile, CEPAL, 2009.

Perrotini, Ignacio, "Restricciones estructurales del crecimiento en México, 1980-2003”, en Economía UNAM, vol. 1, núm. 1, México, unAM, 2004, pp. 86-100.

Pipitone, Ugo, La salida del atraso económico: un estudio histórico comparativo, México, FCE, 1994.

Prebisch, Raúl, "El desarrollo económico de la América Latina y algunos de sus principales problemas", en Revista de Economía Politica, núm. 17, vol. 8, Madrid, Centro de Estudios Políticos y Constitucionales, 1957, pp. 296-314.

Ramos, Joseph, "Un balance de las reformas estructurales neoliberales en América Latina”, Revista de la CEPAL, núm. 62, Chile, Cepal, 1997, pp. 15-38.

Rodrik, Dani, One Economy, Many Recipes: Globalization, Institutions and Economic Growth, USA, Princeton University Press, 2008.

Ros, Jaime, "La desaceleración del crecimiento económico en México desde 1982", en Trimestre Económico, vol. 75, núm. 299, México, FCE, 2008, pp. 537-560.

- Teoría del desarrollo y economía del crecimiento, México, Fondo de Cultura Económica, 2004.

Saboniené, Asta, "The Contradictions of Industrial Policy in the Context of Economic Integration", en Economics and Management, núm. 15, Lituania, Kauno Technologijos Universitetas, 2010, pp. 212-219.

Samaniego, Norma, "El crecimiento explosivo de la economía informal", en Economía UNAM, vol. 5, núm. 13, México, Facultad de Economía, 2008, pp. $30-41$. 
Sánchez, Fernando, Manuel Fernández y Eduardo Pérez, La politica industrial ante la apertura, México, Fondo de Cultura Económica, Secretaría de Comercio y Fomento Industrial y Nacional Financiera, 1994.

Sánchez, Isaac y Edgar Campos, "Industria manufacturera y crecimiento económico en la frontera norte de México", en Región y Sociedad, vol. 22, núm. 49, Hermosillo, Colson, 2010, pp. 45-89.

Sánchez, Isaac, Estancamiento económico e industrias manufactureras regionales en México, 1993-2010: explicación y propuestas, Tijuana, El Colegio de la Frontera Norte, tesis doctoral, 2010.

Smith, Adam, Investigación sobre la naturaleza y causa de la riqueza de las naciones, México, Fondo de Cultura Económica, 2004 (1776).

Thirlwall, Anthony, "A Plain Man's Guide to Kaldor's Growth Laws", en Journal of Post Keynesian Economics, vol. 5, num 3, Londres, M. E. Sharpe, 1983, pp. 345-358.

Tokman, Víctor, "Mercados de trabajo y empleo en el pensamiento económico latinoamericano", en Sunkel, Osvaldo (comp.), El desarrollo desde dentro. Un enfoque neoestructuralista para la América Latina, México, Fondo de Cultura Económica, 1991, pp. 163-191.

Toner, Phillip, Main Currents in Cumulative Causation: the Dynamics of Growth and Development, Londres, Macmillan, 1999.

unCTAD, "Rethinking Industrial Policy", en United Nations Conference on Trade and Development, Discussion Papers, num. 183, Nueva York, 2007.

Verdoorn, Petrus, "Fattori che regolano lo sviluppo della produttivita del lavoro", en L'Industria, num. 1, 1949, pp. 3-10.

Villarreal, René, Industrialización, competitividad y desequilibrio externo en México. Un enfoque macroindustrial y financiero (1929-2010), México, Fondo de Cultura Económica, 2005.

Wells, Heather y Anthony Thirlwall, “Testing Kaldor's Growth Laws Across the Countries of Africa", en African Development Review, vol. 15, num 2-3, Londres, Wiley-Blackwell, 2003, pp. 89-105.

Young, Allyn, "Increasing Returns and Economic Progress", en Economic Journal, vol. 38, num. 152, Londres, Royal Economic Society, 1928, pp. 527-542. 